\title{
Tackling the SARS-CoV-2 main protease using hybrid derivatives of 1,5-disubstituted tetrazole-1,2,3-triazoles: an in silico assay
}

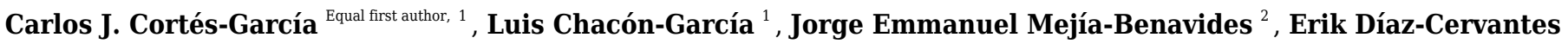
Corresp. Equal first author, 3

${ }^{1}$ Laboratorio de Diseño Molecular, Instituto de Investigaciones Químico-Biológicas, Universidad Michoacana de San Nicolás de Hidalgo, Morelia, Michoacán, México

2 Departamento de Enfermería y Obstetricia, Centro Interdisciplinario del Noreste (CINUG), Universidad de Guanajuato, Tierra Blanca, Guanajuato, México

3 Departamento de Alimentos, Centro Interdisciplinario del Noreste (CINUG), Universidad de Guanajuato, Tierra Blanca, Guanajuato, México

Corresponding Author: Erik Díaz-Cervantes

Email address: e.diaz@ugto.mx

In regard to the actual public health global emergency and, based on the state of the art about the ways to inhibit the SARS-CoV-2 treating the COVID19, a family of 1,5disubstituted tetrazole-1,2,3-triazoles, previously synthesized, have been evaluated through in silico assays against the main protease of the mentioned virus $\left(\mathrm{CoV}-2-\mathrm{M}^{\mathrm{Pro}}\right)$. The results show that three of these compounds present a more favorable interaction with the selected target than the co-crystallized molecule, which is a peptide-like derivative. It was also found that also hydrophobic interactions play a key role in the ligand-target molecular couplings, due to the higher hydrophobic surfaces into the active site. Finally, a pharmacophore model has been proposed based on the results below, and a family of 1,5DT derivatives has been designed and tested with the same methods employed in this work. It was concluded that the compound with the isatin as a substituent (P8) present the higher ligand-target interaction, which makes this a strong drug candidate against COVID19, due can inhibit the CoV-2-MPro protein. 
1 Tackling the SARS-CoV-2 main protease using hybrid 2 derivatives of 1,5-disubstituted tetrazole-1,2,3-triazoles: an in 3 silico assay

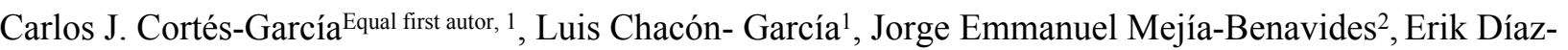
Cervantes Equal first autor, $3^{*}$

${ }^{1}$ Laboratorio de Diseño Molecular, Instituto de Investigaciones Químico-Biológicas, Universidad Michoacana de San Nicolás de Hidalgo. Morelia, Michoacán, México

${ }^{2}$ Departamento de Enfermería y Obstetricia, Centro Interdisciplinario del Noreste (CINUG), Universidad de Guanajuato, Tierra Blanca, Guanajuato, México

${ }^{3}$ Departamento de Alimentos, Centro Interdisciplinario del Noreste (CINUG), Universidad de Guanajuato, Tierra Blanca, Guanajuato, México

ORCID's

C. J. Cortés-García: 0000-0003-4632-6316 ccortes@umich.mx

L. Chacón- García: 0000-0001-8877-4817

lchacon@umich.mx

J. E. Mejía-Benavides: 0000-0002-5061-5316

je.mejiabenavides@ugto.mx

E. Díaz-Cervantes: 0000-0002-1746-3795 


\section{Tackling the SARS-CoV-2 main protease using hybrid derivatives of 1,5-disubstituted tetrazole-1,2,3-triazoles: an in silico assay}

Carlos J. Cortés-García ${ }^{1}$, Luis Chacón- García ${ }^{1}$, Jorge Emmanuel Mejía-Benavides², Erik Díaz-Cervantes ${ }^{3 *}$

${ }^{1}$ Laboratorio de Diseño Molecular, Instituto de Investigaciones Químico-Biológicas, Universidad Michoacana de San Nicolás de Hidalgo. Morelia, Michoacán, México

${ }^{2}$ Departamento de Enfermería y Obstetricia, Centro Interdisciplinario del Noreste (CINUG), Universidad de Guanajuato, Tierra Blanca, Guanajuato, México

${ }^{3}$ Departamento de Alimentos, Centro Interdisciplinario del Noreste (CINUG), Universidad de Guanajuato, Tierra Blanca, Guanajuato, México

Corresponding Author:

Erik Díaz-Cervantes ${ }^{1}$

Universidad de Guanajuato, 37975 Tierra Blanca, Guanajuato, México

Email address: e.diaz@ugto.mx

\section{Abstract}

In regard to the actual public health global emergency and based on the state of the art about the ways to inhibit the SARS-CoV-2 treating the COVID19, a family of 1,5-disubstituted tetrazole1,2,3-triazoles, previously synthesized, have been evaluated through in silico assays against the main protease of the mentioned virus $\left(\mathrm{CoV}-2-\mathrm{M}^{\text {Pro }}\right)$. The results show that three of these compounds present a more favorable interaction with the selected target than the co-crystallized molecule, which is a peptide-like derivative. It was also found that also hydrophobic interactions play a key role in the ligand-target molecular couplings, as a higher number of hydrophobic surfaces make up the active site. Finally, a pharmacophore model has been proposed based on the results below, and a family of 1,5-DT derivatives has been designed and tested with the same methods employed in this work. It was concluded that the compound with the isatin as a substituent (P8) presented the higher ligand-target interaction, making it a strong drug candidate against COVID19, giving its ability to inhibit the $\mathrm{CoV}-2-\mathrm{M}^{\text {Pro }}$ protein. 
78

79

80

81

82

83

84

85

86

87

88

89

90

91

92

93

94

95

96

97

98

99

100

101

102

103

104

105

106

107

108

109

110

111

112

113

114

115

116

\section{Introduction}

Recently, a new kind of coronavirus strain was discovered in Wuhan city in Hubei province, central China. This virus is known as severe acute respiratory syndrome coronavirus 2 (SARS$\mathrm{CoV}-2$ ) and has caused the coronavirus disease 2019 (COVID-19), which has now become a pandemic threat (Gabutti et al. 2020; Gralinski \& Menachery 2020; Jin et al. 2020). At present, SARS-CoV-2 has caused thousands of deaths and more than 5 million people have been infected worldwide, becoming a global public health emergency (Sohrabi et al. 2020). Despite the fact that there are no specific antivirals to treat the COVID-19, the scientific community is using the drug repurposing of some FDA approved drugs such as lopinavir, remdesivir, and chloroquine as a rapid strategy to find a cure (Kandeel \& Al-Nazawi 2020; Li \& Clercq 2020; Li et al. 2020; Shah et al. 2020). Nonetheless, the need to develop a new specific antiviral drug is still urgent.

A quick and efficient way to find a new drug candidate is through computer-aided drug design (CADD) which is a powerful tool used to find new compound by reducing risk, time, and cost of research in the drug discovery process (Baig et al. 2016; Bisht \& Singh 2018; Ferreira et al. 2015; Hoque et al. 2017). Moreover, in February 2020, the first high-resolution crystal structure of the main protease of SARS-CoV-2 was published (PDB code: 6lu7)(Liu et al. 2020b). Such protein is essential in the virus life cycle, thus making it a key target in the quest of developing novel antiviral agents.

Moreover, regards other studies of the main protease of SARS-CoV-2 (CoV-2-M ${ }^{\text {Pro }}$ ), which presents a similar structure to the $\mathrm{M}^{\text {Pro }}$ of the SARS-CoV (He et al. 2020; Liu et al. 2020a; Vellingiri et al. 2020), has been reported that the hydrogen bonds play a key role in the ligandtarget interactions (Chou et al. 2003), as well as in the present year have been perform several studies about the interactions of organic molecules with the CoV-2-MPro(Peele et al. 2020a; Peele et al. 2020b). Also, accord to the state of the art concerning potential candidates that target this specific enzyme highlights 1,2,3-triazoles, synthesized by the Dehaen group, were proposed as potential anti-coronavirus agents (Karypidou et al. 2018). In this context, the present work aimed to evaluate in silico a series of 1,5-disubstituted-tetrazole derivatives which were previously synthesized in our research group (Aguilar-Morales et al. 2019) and whose biological and theoretical essays have not been reported.

Recent reports have shown the plethora of molecules that can interact with the selected target

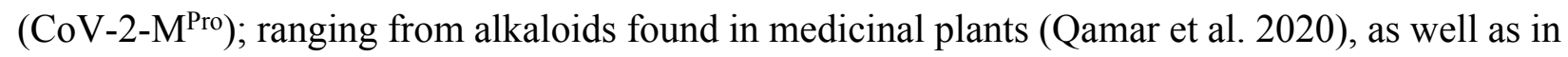
other plants with known health properties, as garlic (Phuong-Thuy et al. 2020), to the use of alpha ketoamide (Zhang et al. 2020). Based on this context, the present work proposes several 1,5disubstituted tetrazole-1,2,3-triazoles as some novel plausible inhibitors of the CoV-2-MPro. The above-mentioned compounds were evaluated through docking assays to obtain the target-ligand interactions that take place. Additionally, a pharmacophore model was performed based on the 
117 target (considering the electrostatic, hydrophobic and hydrogen bond interactions) leading to the

118 to design of a novel family of molecules that can potentially inhibit the CoV-2-M ${ }^{\text {Pro }}$.

119

120

121

122

123

124

125

126

127

128

129

130

131

132

133

134

135

136

137

138

139

140

141

142

143

144

145

146

147

148

149

150

151

152

153

154

155

\section{Computational Methods}

The Cartesian coordinates from the selected target, $\mathrm{CoV}-2-\mathrm{M}^{\mathrm{Pro}}$, were obtained from the protein data bank (PDB code: 6lu7), which was one of the first crystallized structures of the main protease of the SARS-CoV-2 virus. Furthermore, the Chimera package was used to add charges, remove solvents and correct residues of the target structure (Pettersen et al. 2004).

Moreover, the 1,5-disubstituted tetrazole-1,2,3-triazoles and the co-crystallized compound (into the $\mathrm{CoV}-2-\mathrm{M}^{\text {Pro }}$ structure), see Fig. 1, which are considered as ligands, were modeled using the Avogadro software (Jin et al. 2020) and charged with the Chimera package (Pettersen et al. 2004). However, to obtain a better approach, the ligands were optimized at the UFF level (Rappe et al. 1992) using the Gaussian 09 (G09) package (Frisch et al. 2009). Note that, the UFF method was employed due to the good distance and angle bonds it provides to organic molecules, as well as the low computational cost.

Ligand-target interactions were obtained using the Molegro MVD package and the in silico molecular couplings, so-called molecular docking, were performed through the MolDock score function (Thomsen \& Christensen 2006). Also, the electrostatic, hydrogen bond and hydrophilic surfaces interactions were obtained with the same MVD software. Although several methods are frequently reported when studying ligand-target interactions such as the DFTB (Allec et al. 2019; Morao et al. 2017), the selected method was used as a preliminary approach to evaluate these interactions.

Finally, the pharmacophore model was developed using the ZINCPharmer server(Koes \& Camacho 2012), considering the obtained properties obtained throughout the whole study. It is noteworthy to mention that the proposed novel inhibitors underwent the same process as the 1,5disubstituted tetrazole-1,2,3-triazoles and were evaluated using the selected target with the above method.

\section{Results}

\subsection{Molecular Docking}

The specific docking of all the modeled ligands, see Fig. 1, into the active site of the protein CoV2-M $\mathrm{M}^{\text {Pro }}$ is shown in Fig. 2. It is evident that all the ligands docked similarly to the selected target 
156

157

158

159

160

161

162

163

164

165

166

167

168

169

170

171

172

173

174

175

176

177

178

179

180

181

182

183

184

185

186

187

188

189

190

191

192

193

194

195

and interacted with the catalytic triad residues, such interaction will be explained in the discussion section.

Table 1 shows the hydrogen bond energies, the electrostatic interactions, and the LE values obtained for the selected ligands. Additionally, Fig. 3 shows the active site of the target, with the co-crystalized ligand and two of the best ligands interacting.

\subsection{Hydrogen bonds, electrostatic interactions and hydrophobic interactions}

The hydrogen bond and electrostatic interactions between the selected target and the ligand $\mathbf{1 e}$, which is the compound with the most favorable ligand-target interactions, are depicted in Fig. 4. The principal interactions are those with histidine residues, as well as one with serine and glutamine.

The hydrophobicity surfaces of the active site show that in the deep zone of the cavity a hydrophobic zone can be found, as shown in Fig. $\mathbf{5}$ in blue colored surfaces. However, the front of the cavity and one site in the upper-left zone shows a higher hydrophilic site, depicted in red color in Fig. 5.

\subsection{Pharmacophore model}

Taken into account the results gathered, especially the docking results obtained by both, the $1 \mathrm{e}$ ligand and the co-crystallized ligand, and taken the hydrophobic surfaces as one of the main interactions, a pharmacophore model was developed. The principal aim in developing this model was to predict and propose the molecular fragments that are necessary to interact with CoV-2$\mathrm{M}^{\text {Pro }}$, which would result in virus inhibition.

The proposed pharmacophore model is shown in Fig. 6, and consists of ten principal components: two hydrophobic fragments (Hy, depicted in green color), one aromatic fragment ( $\mathrm{Ar}$, colored in blue color), three hydrophobic-aromatic fragments (Hy-Ar, represented in purple color), two hydrogen donor fragments (HD, depicted in gray color) and two hydrogen acceptor fragments (colored in orange color).

\subsection{Proposing molecules}

Based on the obtained results and considering the pharmacophore model, a series of ten 1,5disubstituted tetrazole-1,2,3-triazoles have been proposed as inhibitors of the $\mathrm{CoV}-2-\mathrm{M}^{\mathrm{Pro}}$, which are depicted in Fig. 7. 
Furthermore, Fig. 8A shows that that molecule P8 prefers to interact in the right side of the molecule in a similar manner as the co-crystallized ligand and 1e compounds. The structure of compound P8 is located in the deep of the active site.

200

Finally, Fig. 9 shows the molecules 1e and P8 in the pharmacophore model, and reveals the occupied space by these molecules into the pharmacophore model.

\section{Discussion}

\subsection{Molecular Docking}

To evaluate the best ligand docked in the selected target, CoV-2-M ${ }^{\text {Pro }}$, the MolDock score energy was considered as a parameter of measurement. Furthermore, the ligand efficiency (LE = Energy/No. of heavy atoms) was used to determine with better precision the ligand-target binding strength. This parameter gives the energy provided per atom in the ligand-target interaction, making it a better way of comparison between ligands with different number of atoms, see Table 1.

In comparison with the co-crystallized ligand reported in the PDB file, $1 \mathrm{e}$ is $0.04 \mathrm{kcal} / \mathrm{mol} \mathrm{more}$ stable (Liu et al. 2020b). Also, P8 is the molecule with highest ligand-target interaction energy.

Moreover, the hydrogen bond $\left(\mathrm{H}_{\mathrm{bond}}\right)$, electrostatic (Elstat) interactions and the Van der Waals energies (VdW) are shown in Table 1, demonstrating that the VdW the limiting energy in obtaining a better ligand-target interaction for this kind of systems. In other hand, best ligands show the most favorable VdW energies. However, the state of the art regarding this protease indicates that the hydrogen bond interactions are one of the most important energies, especially with the amides of the catalytic triad residues (Gly143, Cys145, and Ser144) (Zhang et al. 2020). Note that table 1 includes compounds P1-10, which are the designed potential inhibitors presented in this work and will be boarded in section 4.4

In respect to the docked cavity, our results are in line with the results obtained by other authors, and show the interactions of the ligands into the active site of the protein, in the so-called catalytic triad (Gly143, Ser144, and Cys145), see Fig. 3. At the same time, the His41 and the Asp187 are important residues in the onset of the electronic transfer, which is the key mechanism in peptide bond rupture for this kind of protease. Other key fragments in the oxyanion hole includes the Gly143 and Ser144 residues, which according to Warshel and co-workers (Kamerlin et al. 2010; Mukherjee \& Warshel 2012), stabilize the anionic intermediary. This helps identify the active site and is a way to corroborate that this cavity is the target site of the protein. 
237 Fig. 3 shows first the co-crystallized molecule (a peptide like derivative) which directly interacts 238 with the catalytic triad and part of the molecule dock perfectly in almost the whole cavity. 239 Furthermore, Fig. 3B depicts the two best ligands interacting in a similar manner to the co240 crystallized molecule, but filling the right site of the computed cavity. This behavior might 241 explain the most favorable interactions seen when comparing them with the co-crystallized 242 molecule, see Table 1.

\subsection{Hydrogen bonds, electrostatic interactions and hydrophobic interactions}

The 1e ligand presents hydrogen bond interactions with Ser144 and His164, see Fig. 4A. Note that these are residues of the catalytic site. Furthermore, Fig 4B shows the same ligand interacting with His41, His163, Glu166, and His172 via electrostatic forces, in which the repulsive electrostatic interactions are more prominent than the attractive ones. This, as a result of the similar partial charge (positive-positive or negative-negative) between 1e and histidine residues. This kind of interaction plays a key role in the final conformation of the bioactive posse. Generally, the electrostatic interactions are one of the limiting energies in the ligand-target coupling and ligand 1e shows a value of -0.65 , being this one of the highest ones of the table.

To better evaluate the ligand-target interactions, it is necessary to carry out an analysis of the hydrophobic surfaces of the selected cavity. Fig 5A shows the interactions between the cocrystallized ligand and the selected target, from a hydrophobic behavior. The ligand takes a conformation into the cavity occupying only the deep zone of the active site (the more hydrophobic site) and avoids the interactions with the front site of the cavity. Note that ligand 1e shows a similar interaction with the active site, see Fig. 5B.

Contrary to the co-crystallized ligand, compound $1 \mathrm{e}$ does not cross the cavity space in the right site. However, in interacts in the deep site of the cavity, docking less in the left site of the surface. Note that ligand 1e presents higher L.E., than the co-crystallized ligand, see Table 1. Therefore, it is clear that the presence of aromatic and hydrophobic rings in both molecules is essential and key for better interactions. The hydrophilic interactions are practically negligible.

\subsection{Pharmacophore model}

Analyzing Fig6, it is clear that the low side of the model needs mostly hydrophobic fragments, and in the top, the fragments are HD and HA. The volume of the pharmacophore model makes us 
274

275

276

277

278

279

280

281

282

283

284

285

286

287

288

289

290

291

292

293

294

295

296

297

298

299

300

301

302

303

304

305

306

307

308

309

310

311

312

think that to tackle the $\mathrm{M}^{\text {Pro }}$ of the SARS-Cov-2 virus, it is necessary a molecule with rings along their whole structure.

Highlights that with the proposed pharmacophore model can be design a family of compounds which can inhibit the $\mathrm{M}^{\text {Pro }}$, avoiding the virus replication and promoting the cure for the COVID19.

\subsection{Proposing molecules}

Based on the obtained results and considering the pharmacophore model, a series of ten 1,5disubstituted tetrazole-1,2,3-triazoles have been proposed as inhibitors of the CoV-2-M $\mathrm{M}^{\text {Pro }}$, which are depicted in Fig. 7. As shown in Table 1, the P8 and P10 designed molecules present the more favorable interactions with the selected target as they show a more negative LE value than the other evaluated compounds. Note that, six of the ten designed molecules exhibit better interaction with the CoV-2-M ${ }^{\text {Pro }}$ than the co-crystallized molecules, which is the reference molecule.

On the other hand, the compound $\mathrm{P} 8$ has an isatin scaffold (1H-indole-2,3-dione) as part of its structure, which is considered a privileged structure given its broad biological and pharmacological activity. Some of which include antibacterial, anticancer, antitubercular, antimalarial, antifungal, anticancer, anti-HIV, and in general antiviral (Varun et al. 2019). Analyzing the bio-active possess of compound $\mathrm{P} 8$, it is seen that it promotes an intramolecular stabilization due to two stacking interactions: one with the triazole ring and the other with the benzene ring, face-to-edge, and faceto-face, respectively.

Fig. 8 shows the principal hydrophobic interactions between $\mathrm{P} 8$ and the Cov-2-M $\mathrm{M}^{\text {Pro }}$, depicted in blue surfaces. These results can be explained by the higher quantity of rings in the P8 structures, which could promote hydrophobic interactions.

In the case of the hydrogen bond interactions, molecule P8 interacts not only with the catalytic triad, specifically with the Ser144 and Cys145, and presents a higher number of interactions with other residues that include Ser1 and Asn142. The last one promotes a higher $\mathrm{H}_{\text {bond }}$ energy than compound 1e, see Table 1. In fact, (Liu et al. 2020b) mention that hydrogen bond interactions play a key role in the ligand-target interaction as highlighted in the state of the art. Moreover, the electrostatic interactions between P8 and the selected target take place at the residues His41, His163, Glu166, and His172 residues, which in terms of Elstat energy, do not promote a favorable interaction (To understand better the behavior of the electrostatic interactions as a function of the different moieties in the studied molecules, the molecular electrostatic potential surfaces are depicted in Supplemental Files).

Peer] Phy. Chem. reviewing PDF | (PCHEM-2020:05:48566:1:2:NEW 1 Jun 2020) 
313 On the other hand, molecule 1e, which was previously synthesized by some of us, and the designed 314 compound P8 were evaluated into the pharmacophore model and analyzed through the segments 315 docked with the proposed structure. Fig. 9A shows the molecule 1e in the pharmacophore model, 316 which reveals that this molecule needs some components to complete all the pharmacophore 317 fragments. Specifically, it needs an aromatic moiety, as well as an HD and HA fragments in the 318 top of the molecule.

319

320

321

322

323

324

325

326

327

328

329

330

331

332

333

334

335

336

337

338

339

340

341

342

343

344

345

346

347

348

349

350

351

352

Finally, Fig. 9B depicts the P8 structure into the pharmacophore model and shows that this molecule only an Hy and one HD fragments in order to complete all the requirements. Analyzing the results, it is clear that to obtain some better molecules that could inhibit the Cov-2-M $\mathrm{M}^{\text {Pro }}$ it is necessary to have a system that includes some rings in their structure. Also, the right side is the more important site of the cavity, as long as the size of the molecule does not overpass the size of the cavity.

\section{Conclusions}

A family of compounds previously synthesized by some of us was tested to inhibit the protein Cov-2-M $\mathrm{M}^{\text {Pro }}$, the results show that three of these compounds present a more favorable interaction with the selected target than the co-crystallized molecule, which is a peptide-like derivative. Moreover, although the fact that hydrogen bond interactions are mentioned in the state of the art about the selected protease, it can also be found that the electrostatic interactions and main the hydrophobic interactions play a key role in the ligand-target molecular couplings.

At the same time, the results reveal that a molecule can couple into the active site, which presents higher hydrophobic surfaces. Thus, in the quest to develop potential candidates it is essential to synthesize some molecules with a higher number of aromatic rings in their structures. Note that the residues of the active site interact in a stronger way with the best coupled ligand.

Finally, a pharmacophore model has been designed and used to propose a new family of 1,5disubstituted tetrazole-1,2,3-triazoles derivatives. These compounds are potential candidates to be synthesized as a perspective of this work. Based on the obtained results, the best ligands were coupled with the pharmacophore model, highlights the importance of the isatin moiety. Also, the pharmacophore model revealed that derivatives bearing the isatin substituent have a higher potential in the design of new drugs against the SARS-Cov-2. Hydrophobic and stacking interactions also play a key role in the design of new drug candidates to treat the COVID19.

Peer] Phy. Chem. reviewing PDF | (PCHEM-2020:05:48566:1:2:NEW 1 Jun 2020) 
353

354

355

356

357

358

359

360

361

362

363

365

366

367

368

369

370

371

372

373

374

375

376

377

378

379

380

381

382

383

384

385

386

387

388

389

390

391

392

\section{Acknowledgements}

We are grateful to the Laboratorio Nacional de Caracterización de Propiedades Fisicoquímicas y Estructura Molecular (UG-UAA-CONACYT, Project: 123732) for the computing time provided. Erik Díaz-Cervantes acknowledge to the SICES by the support in the project: IJ-19-77 (Programa de empuje científico y tecnológico modalidad “Apoyo a Investigadores Jóvenes"), also acknowledge to Citlalli, Emily and Naomi.

\section{Competing Interests}

The authors declare that they have no competing interests

\section{References}

Aguilar-Morales CM, Loera Dd, Contreras-Celedón C, Cortés-García CJ, and Chacón-García L. 2019. Synthesis of 1,5-disubstituted tetrazole-1,2,3 triazoles hybrids via Ugi-azide/CuAAC. Synth Commun 49:2086-2095. https://doi.org/10.1080/00397911.2019.1616301

Allec SI, Sun Y, Sun J, Chang C-eA, and Wong BM. 2019. Heterogeneous CPU+GPU-Enabled Simulations for DFTB Molecular Dynamics of Large Chemical and Biological Systems. J Chem Theory Comput 15:2807-2815. https://doi.org/10.1021/acs.jctc.8b01239

Baig MH, Ahmad K, Roy S, Ashraf JM, M MA, Siddiqui MH, Khan S, Kamal MA, Provazník I, and Choi I. 2016. Computer Aided Drug Design: Success and Limitations. Curr Pharm Design 22:572-581. http:// https://doi.org/10.2174/1381612822666151125000550

Bisht N, and Singh BK. 2018. ROLE OF COMPUTER AIDED DRUG DESIGN IN DRUG DEVELOPMENT AND DRUG DISCOVERY. Int $J$ Pharm Sci Res 9:1405-1415. http://dx.doi.org/10.13040/IJPSR.0975-8232.9(4).1405-15

Chou K-C, Wei D-Q, and Zhong W-Z-. 2003. Binding mechanism of coronavirus main proteinase with ligands and its implication to drug design against SARS. Biochem Biophys Res Commun 308:148-151. http://doi.10.1016/j.bbrc.2003.09.053

Ferreira LG, Santos RNd, Oliva G, and A. D. Andricopulo. 2015. Molecular Docking and Structure-Based Drug Design Strategies. Molecules 20:13384-13421. https://doi.org/10.3390/molecules200713384 
393 Frisch MJ, Trucks GW, Schlegel HB, Scuseria GE, Robb MA, Cheeseman JR, Scalmani G, Barone 394 V, Mennucci B, Petersson GA, Nakatsuji H, Caricato M, Li X, Hratchian HP, Izmaylov AF, Bloino 395 J, Zheng G, Sonnenberg JL, Hada M, Ehara M, Toyota K, Fukuda R, Hasegawa J, Ishida M, 396 Nakajima T, Honda Y, Kitao O, Nakai H, Vreven T, Jr. JAM, Peralta JE, Ogliaro F, Bearpark M, 397 Heyd JJ, Brothers E, Kudin KN, Staroverov VN, Kobayashi R, Normand J, Raghavachari K, 398 Rendell A, Burant JC, Iyengar SS, Tomasi J, Cossi M, Rega N, Millam JM, Klene M, Knox JE, 399 Cross JB, Bakken V, Adamo C, Jaramillo J, Gomperts R, Stratmann RE, Yazyev O, Austin AJ, 400 Cammi R, Pomelli C, Ochterski JW, Martin RL, Morokuma K, Zakrzewski VG, Voth GA, 401 Salvador P, Dannenberg JJ, Dapprich S, Daniels AD, Farkas Ö, Foresman JB, Ortiz JV, Cioslowski 402 J, and Fox DJ. 2009. Gaussian 09. C.01 ed: Wallingford CT.

403

404

Gabutti G, d'Anchera E, Sandri F, Savio M, and Stefanati A. 2020. Coronavirus: Update Related 405 to the Current Outbreak of COVID-19. Infect Dis Ther. https://doi.org/10.1007/s40121-020406 00295-5

407

408

Gralinski LE, and Menachery VD. 2020. Return of the Coronavirus: 2019-nCoV. Viruses 12:135. 409 https://doi.org/10.3390/v12020135

410

411

412

413

414

415

416

417

418

419

420

421

422

423

424

425

426

427

428

429

430

431

432

He J, Tao H, Yan Y, Huang S, and Xiao Y. 2020. Molecular Mechanism of Evolution and Human Infection with SARS-CoV-2. Viruses 12:428. https://doi.org/10.3390/v12040428

Hoque I, Chatterjee A, Bhattacharya S, and Biswas R. 2017. An Approach of Computer-Aided Drug Design (CADD) Tools for In Silico Pharmaceutical Drug Design and Development. Int J Adv Res Biol Sci 4:60-71. http://dx.doi.org/10.22192/ijarbs.2017.04.02.009

Jin Y, Yang H, Ji W, Wu W, Chen S, Zhang W, and Duan G. 2020. Virology, Epidemiology, Pathogenesis, and Control of COVID-19. Viruses 12:322. https://doi.org/10.3390/v12040372

Kamerlin SCL, Chu AT, and Warshel A. 2010. On Catalytic Preorganization in Oxyanion Holes: Highlighting the Problems with the Gas-Phase Modeling of Oxyanion Holes and Illustrating the Need for Complete Enzyme Models. J Org Chem 75:6391-6401. https://doi.org/10.1021/jo100651s

Kandeel M, and Al-Nazawi M. 2020. Virtual screening and repurposing of FDA approved drugs against COVID-19 main protease. Life Sci. https://doi.org/10.1016/j.lfs.2020.117627

Karypidou K, Ribone SR, Quevedo MA, Persoons L, Pannecouque C, Helsen C, Claessens F, and Dehaen W. 2018. Synthesis, biological evaluation and molecular modeling of a novel series of fused 1,2,3-triazoles as potential anti-coronavirus agents. Bioorg Med Chem Lett 28:3472-3746. https://doi.org/10.1016/j.bmcl.2018.09.019

Peer] Phy. Chem. reviewing PDF | (PCHEM-2020:05:48566:1:2:NEW 1 Jun 2020) 
434 Koes DR, and Camacho CJ. 2012. ZINCPharmer: pharmacophore search of the ZINC database

435 Nucleic Acids Res 40:W409-W414. https://doi.org/10.1093/nar/gks378

436

437 Li G, and Clercq ED. 2020. Therapeutic options for the 2019 novel coronavirus (2019-nCoV). Nat

438 Rev Drug Discov 19:149-150. https://doi.org/10.1038/d41573-020-00016-0

439

440 Li H, Liu S, Yu X, Tang S, and Tang C. 2020. Coronavirus disease 2019 (COVID-19): current 441 status and future perspectives. Int $J$ Antimicrob $\mathrm{Ag}$.

442 https://doi.org/10.1016/j.ijantimicag.2020.105951

443

444 Liu C, Zhou Q, Li Y, Garner LV, Watkins SP, Carter LJ, Smoot J, Gregg AC, Daniels AD, Jervey 445 S, and Albaiu D. 2020a. Research and Development on Therapeutic Agents and Vaccines for 446 COVID-19 and Related Human Coronavirus Diseases. ACS Cent Sci 6:315-331. 447 https://doi.org/10.1021/acscentsci.0c00272

448

449 Liu X, Zhang B, Jin Z, Yang H, and Rao Z. 2020b. The crystal structure of COVID-19 main 450 protease in complex with an inhibitor N3. 2020-02-05 ed: Protein Data Bank. 451 https://doi.org/10.2210/pdb6LU7/pdb

452

Morao I, Fedorov DG, Robinson R, Southey M, Townsend-Nicholson A, Bodkin MJ, and Heifetz 454 A. 2017. Rapid and accurate assessment of GPCR-ligand interactions Using the fragment molecular orbital-based density-functional tight-binding method. J Comput Chem 38:1987-1990. http://doi.org/10.1002/jcc. 24850

Mukherjee S, and Warshel A. 2012. Realistic simulations of the coupling between the protomotive force and the mechanical rotation of the F0-ATPase. PNAS 109:14876-14881. https://doi.org/10.1073/pnas.1212841109

461

Peele KA, Chandrasai P, Srihansa T, Krupanidhi S, Sai AV, Babu DJ, Indira M, Reddy AR, and 463 Venkateswarulu TC. 2020a. Molecular docking and dynamic simulations for antiviral compounds 464 against SARS-CoV-2: A computational study. Inf Med Unlocked. https://doi.org/10.1016/j.imu.2020.100345 
471 Pettersen EF, Goddard TD, Huang CC, Couch GS, Greenblatt DM, Meng EC, and Ferrin TE. 2004. 472 UCSF Chimera--a visualization system for exploratory research and analysis. $J$ Comput Chem 473 25:1605-1612. https://doi.org/10.1002/jcc.20084

474

475 Phuong-Thuy BT, Ai-My TT, Thanh-Hai NT, Trung-Hieu L, Thai-Hoa T, Phuong-Loan HT, 476 Thanh-Triet N, Van-Anh TT, Tu-Quy P, Van-Tat P, Van-Hue N, Tuan-Quang D, Tien-Trung N, 477 Thanh-Tung V, Huynh LK, and Ai-Nhung NT. 2020. Investigation into SARS-CoV-2 Resistance 478 of Compounds in Garlic Essential Oil. ACS Omega. https://doi.org/10.1021/acsomega.0c00772

479

480

Qamar MTU, Alqahtani SM, Alamri MA, and Chen LL. 2020. Structural basis of SARS-CoV-2 481 3CLpro and anti-COVID-19 drug discovery from medicinal plants. J Pharm Sci 533. 482 483 https://dou.org/10.1016/j.jpha.2020.03.009

485

486

487

488

489

490

491

492

493

494

495

496

497

498

499

500

501

502

503

504

505

506

507

508

Rappe AK, Casewit CJ, Colwell KS, III WAG, and Skiff WM. 1992. J Am Chem Soc 114:1002410035. https://doi.org/10.1021/ja00051a040

Shah B, Modi P, and Sagar SR. 2020. In silico Studies on Therapeutic Agents for COVID-19: Drug Repurposing Approach. Life Sci. https://doi.org/10.1016/j.1fs.2020.117652

Sohrabi C, Alsafi Z, O'Neill N, Khan M, Kerwan A, Al-Jabir A, Iosifidis C, and Agha R. 2020. World Health Organization declares global emergency: A review of the 2019 novel coronavirus (COVID-19). Int J Surg 76:71-76. https://doi.org/10.1016/j.ijsu.2020.02.034

Thomsen R, and Christensen MH. 2006. MolDock: a new technique for high-accuracy molecular docking. J Med Chem 49:3315-3321. https://dx.doi.org/10.1021/jm051197e

Varun, Sonam, and Kakkar R. 2019. Isatin and its derivatives: A survey of recent syntheses, reactions, and applications. Med Chem Commun 10:351-368. https://doi.org/10.1039/C8MD00585K

Vellingiri B, Jayaramayya K, Iyer M, Narayanasamy A, Govindasamy V, Giridharan B, Ganesan S, Venugopal A, Venkatesan D, Ganesan H, Rajagopalan K, Rahman PK, Cho S-G, N. S. Kumar, and Subramaniam MD. 2020. COVID-19: A promising cure for the global panic. Sci Total Environ 725:138277. https://doi.org/10.1016/j.scitotenv.2020.138277

Zhang L, Lin D, Sun X, Curth U, Drosten C, Sauerhering L, Becker S, Rox K, and Hilgenfeld R. 2020. Crystal structure of SARS-CoV-2 main protease provides a basis for design of improved $\alpha$ ketoamide inhibitors. Science. https://doi.10.1126/science.abb3405

Peer] Phy. Chem. reviewing PDF | (PCHEM-2020:05:48566:1:2:NEW 1 Jun 2020) 


\section{Table 1 (on next page)}

Interaction energies between the modeled ligands and the protein CoV-2-M Pro.

All the units are represented in $\mathrm{kcal} / \mathrm{mol}$. $\mathrm{H}_{\text {Bond }}$ means the hydrogen bond interactions, Elstat the electrostatic energies, VdW indicates the Van der Waals energy and, LE is the ligand efficiency ( $L E=E /$ No heavy atoms). 


\begin{tabular}{|c|c|c|c|c|c|}
\hline Molecule & $\mathbf{E}$ & HBond & Electro & VdW & LE \\
\hline P8 & -255.79 & -7.99 & -0.11 & -60.73 & -5.44 \\
\hline P10 & -210.29 & -8.31 & 0.74 & -56.38 & -5.26 \\
\hline $1 e$ & -181.75 & -2.52 & -0.65 & -52.43 & -5.19 \\
\hline P7 & -212.54 & -6.86 & 0.05 & -51.71 & -5.18 \\
\hline $1 \mathrm{~h}$ & -174.15 & -5.64 & -0.45 & -49.54 & -5.12 \\
\hline P9 & -213.61 & -11.93 & -0.38 & 22.42 & -5.09 \\
\hline P6 & -198.34 & -8.17 & 0.03 & -54.14 & -5.09 \\
\hline P5 & -198.33 & -5.24 & -0.72 & -49.06 & -5.09 \\
\hline $1 \mathrm{k}$ & -157.03 & -8.32 & -0.54 & -22.57 & -5.07 \\
\hline Co-crystal & -211.79 & -8.38 & -0.61 & -54.52 & -5.04 \\
\hline $1 a$ & -155.38 & -6.86 & -0.10 & -42.84 & -5.01 \\
\hline $\mathrm{P} 1$ & -215.37 & -11.53 & 1.72 & -66.12 & -5.01 \\
\hline $1 \mathrm{j}$ & -155.23 & -5.05 & -0.42 & -44.01 & -5.01 \\
\hline $1 \mathrm{~g}$ & -169.91 & -6.86 & 0.58 & 53.31 & -5.00 \\
\hline $1 \mathrm{i}$ & -159.14 & -10.08 & 0.09 & -26.84 & -4.97 \\
\hline P2 & -213.91 & -7.78 & 0.82 & -34.42 & -4.86 \\
\hline $1 \mathrm{~m}$ & -178.32 & -0.82 & -0.78 & -38.11 & -4.82 \\
\hline P3 & -201.55 & -13.36 & -0.37 & 62.82 & -4.80 \\
\hline 10 & -193.90 & -9.15 & -0.09 & -51.42 & -4.73 \\
\hline $1 f$ & -150.08 & -6.83 & 0.57 & -28.37 & -4.69 \\
\hline P4 & -195.21 & -6.29 & -1.00 & -59.43 & -4.65 \\
\hline $1 b$ & -147.94 & -10.63 & -0.13 & -38.52 & -4.62 \\
\hline $1 c$ & -156.95 & -12.12 & -0.05 & -39.49 & -4.62 \\
\hline $1 d$ & -151.19 & -11.98 & -0.13 & -40.69 & -4.58 \\
\hline $1 n$ & -177.09 & -6.68 & -0.57 & -26.16 & -4.54 \\
\hline 11 & -151.39 & -9.55 & -0.03 & -28.60 & -4.45 \\
\hline
\end{tabular}


Figure 1

Modeled co-crystallized and 1,5-disubstituted tetrazole-1,2,3-triazoles

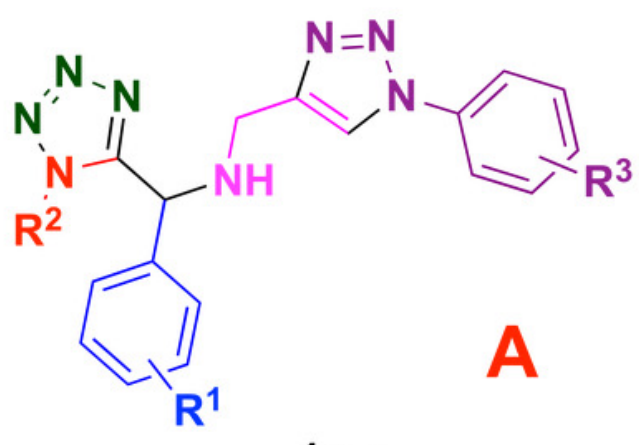

1a-o

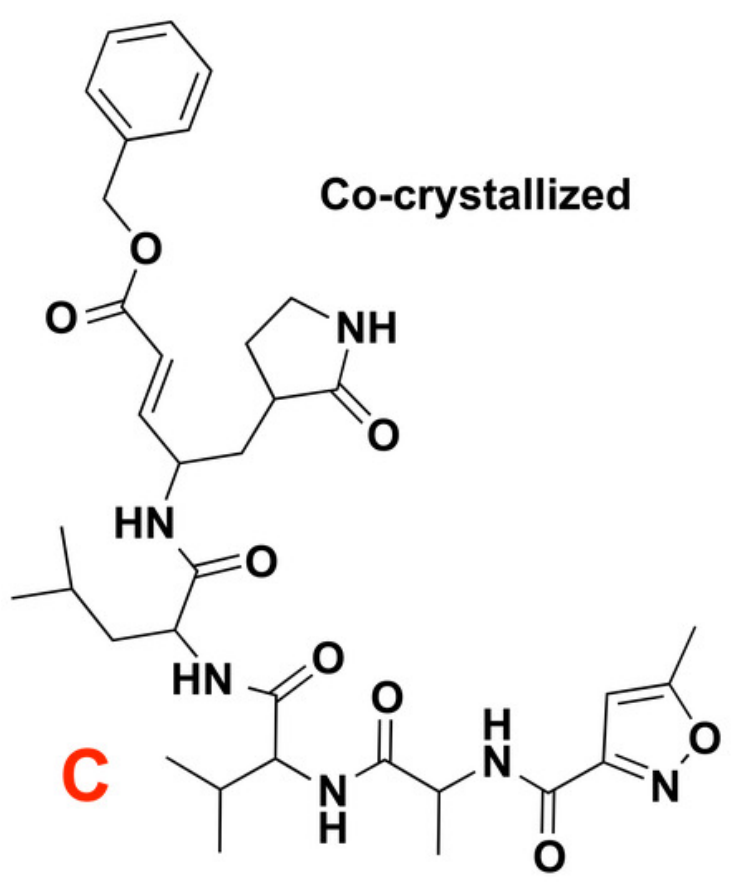

\begin{tabular}{|c|c|c|c|}
\hline Compound & $\mathbf{R}^{\mathbf{1}}$ & $\mathbf{R}^{\mathbf{2}}$ & $\mathbf{R}^{\mathbf{3}} \mathbf{B}$ \\
\hline $\mathbf{1 a}$ & $\mathrm{H}$ & $t$-Bu & $4-\mathrm{CN}$ \\
\hline $\mathbf{1 b}$ & $4-\mathrm{F}$ & $t$-Bu & $4-\mathrm{CN}$ \\
\hline $\mathbf{1 c}$ & $4-\mathrm{Br}$ & $\mathrm{Cy}$ & $4-\mathrm{CN}$ \\
\hline $\mathbf{1 d}$ & $4-\mathrm{Me}$ & $t$-Bu & $4-\mathrm{CN}$ \\
\hline $\mathbf{1 f}$ & $4-\mathrm{Me}$ & $\mathrm{Cy}$ & $4-\mathrm{CN}$ \\
\hline $\mathbf{1 g}$ & $2-\mathrm{Cl}$ & $t$-Bu & $4-\mathrm{CN}$ \\
\hline $\mathbf{1 h}$ & $2,4,5-\mathrm{HriMe}$ & $t-\mathrm{Bu}$ & $4-\mathrm{CN}$ \\
\hline $\mathbf{1 i}$ & $\mathrm{H}$ & $\mathrm{Cy}$ & $4-\mathrm{Cl}$ \\
\hline $\mathbf{1 j}$ & $4-\mathrm{F}$ & $t-\mathrm{Bu}$ & $4-\mathrm{Cl}$ \\
\hline $\mathbf{1 k}$ & $4-\mathrm{Br}$ & $t-\mathrm{Bu}$ & $4-\mathrm{Cl}$ \\
\hline $\mathbf{1 l}$ & $4-\mathrm{OMe}$ & $t$-Bu & $4-\mathrm{NHCOMe}$ \\
\hline $\mathbf{1 m}$ & $4-\mathrm{OMe}$ & $\mathrm{Cy}$ & $4-\mathrm{NHCOMe}$ \\
\hline $\mathbf{1 n}$ & $4-\mathrm{Br}$ & $t-\mathrm{Bu}$ & $2-\mathrm{COPh}-4 \mathrm{Cl}$ \\
\hline $\mathbf{1 0}$ & $2-\mathrm{F}$ & $\mathrm{Cy}$ & $2-\mathrm{COPh}-4 \mathrm{Cl}$ \\
\hline & & & \\
\hline
\end{tabular}




\section{Figure 2}

Docking of the 1,5-disubstituted tetrazole-1,2,3-triazoles with the protein CoV-2-M ${ }^{\mathrm{pro}}$.

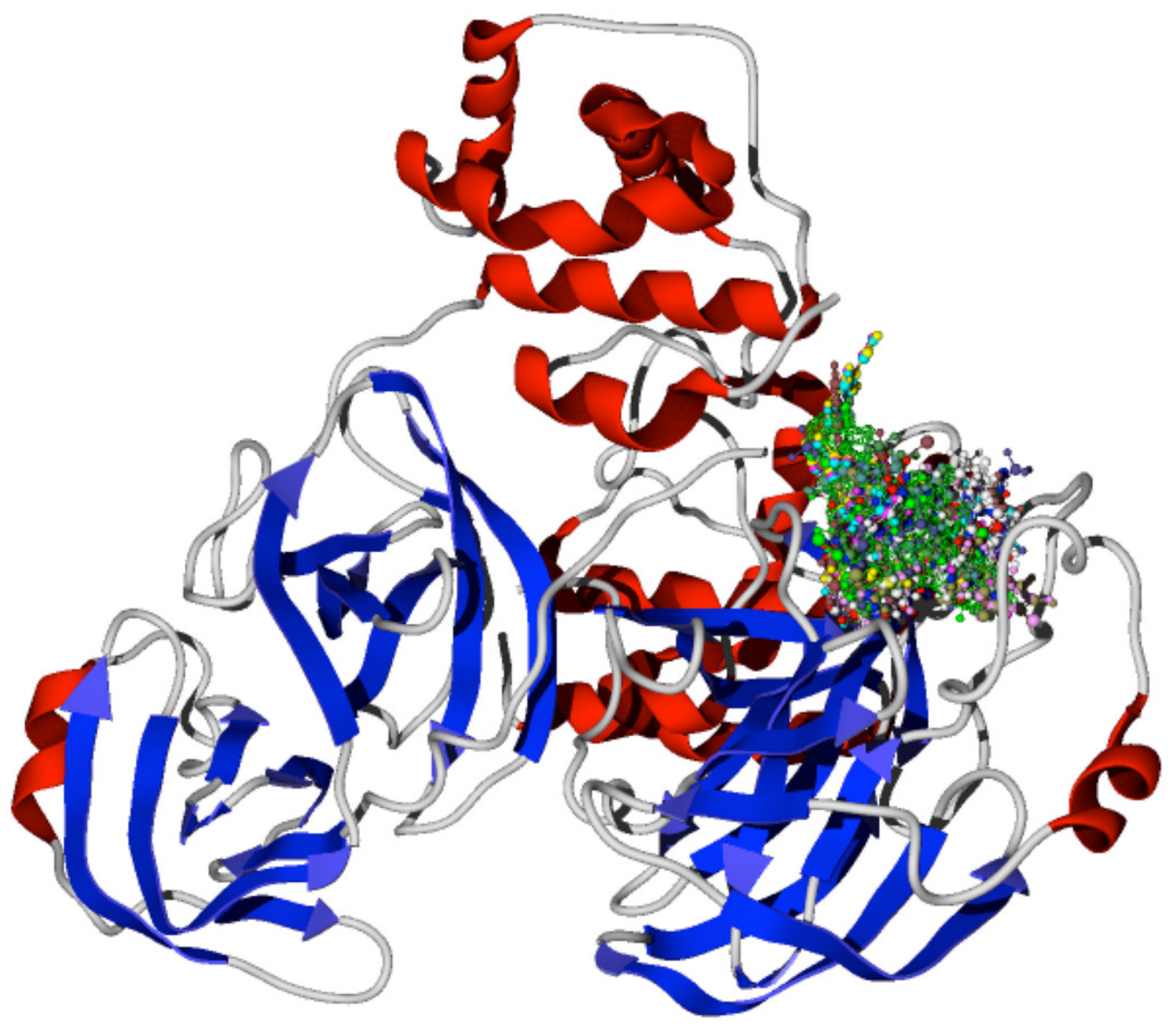


Figure 3

Catalytic site of the CoV-2-Mpro protein

A) The co-crystalized ligand and B) the two best ligands interacting into the catalytic site of the Cov-2-MPro protein
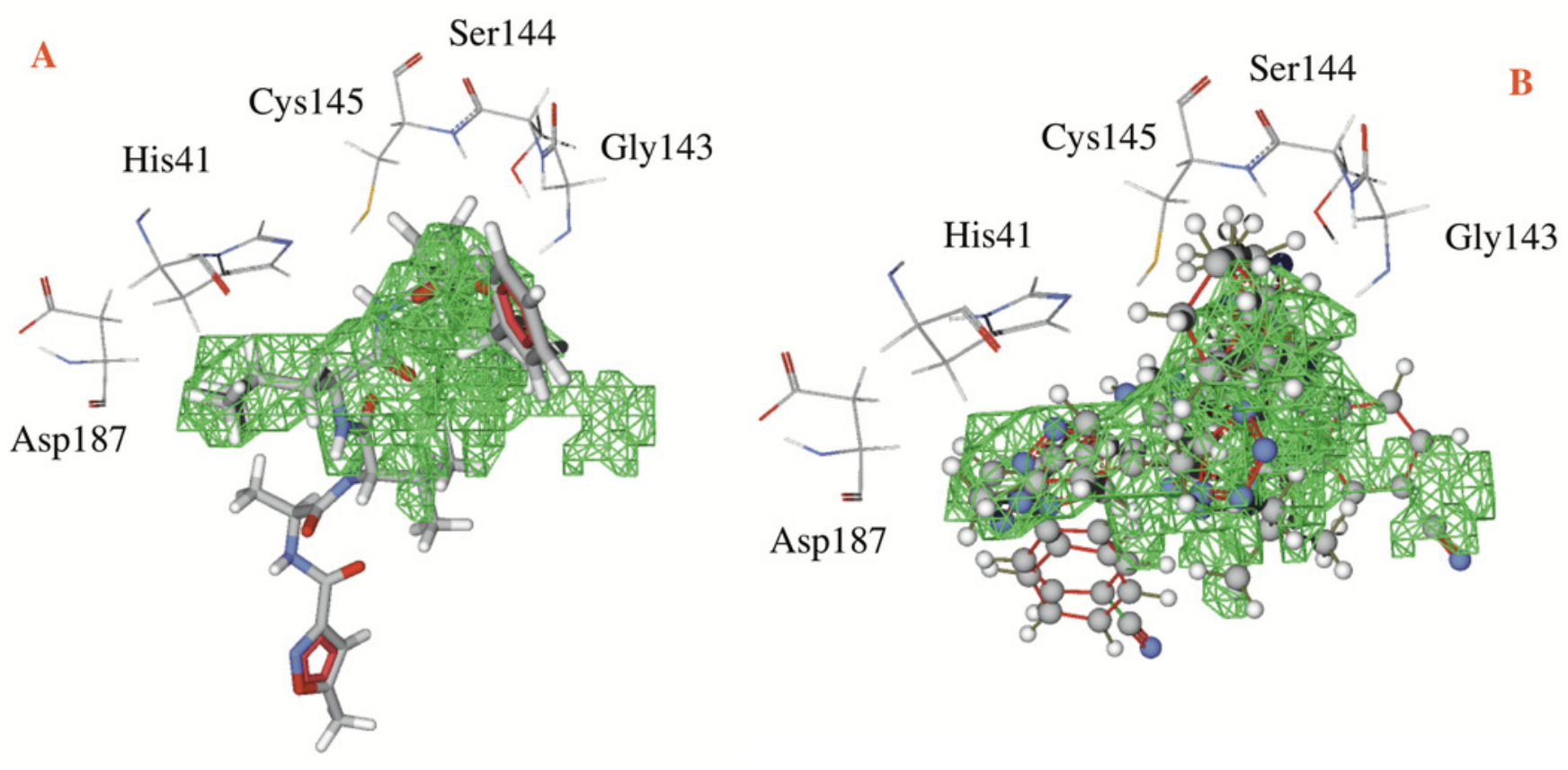
Figure 4

Hydrogen bond and electrostatic interactions between the CoV-2-M ${ }^{\text {Pro }}$ protein and the best ligand 1e.

Dotted blue lines represent the hydrogen bond interaction, as well as dotted green lines, represent the attractive electrostatic interactions and dotted red lines the repulsive electrostatic interactions.
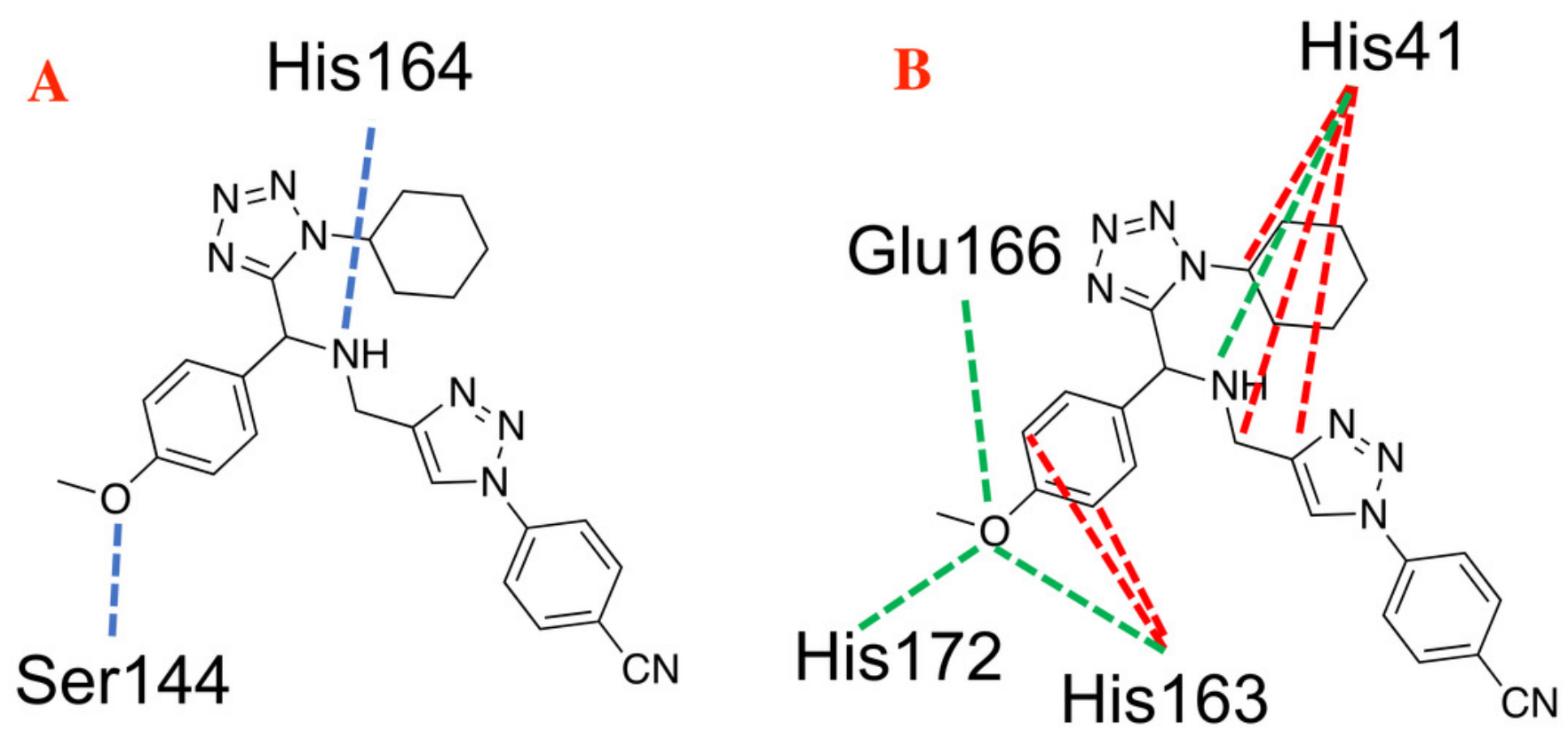


\section{Figure 5}

Hydrophobic interactions between the CoV-2-M pro protein and the main ligands

Hydrophobic interactions between the Cov-2-MPro protein and A) the co-crystallized ligand, and B) 1e. Blue surfaces represent hydrophobic sites, red surfaces are hydrophilic zones
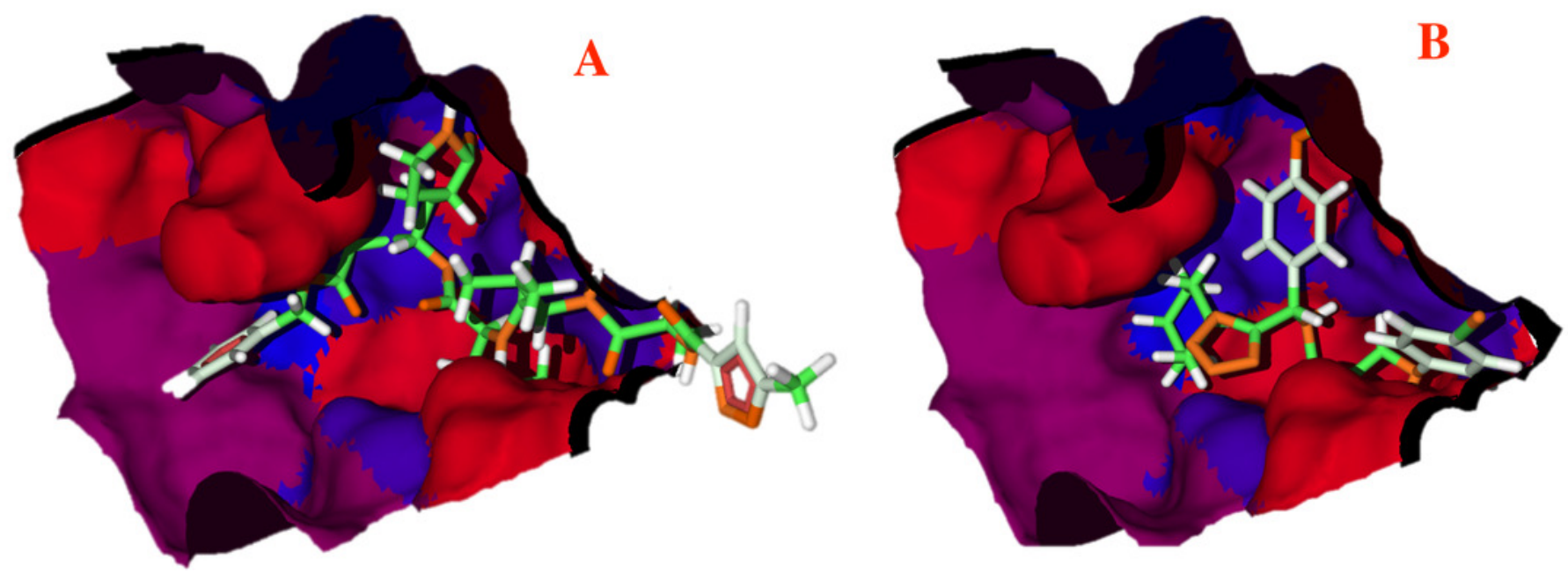
Figure 6

Pharmacophore model for the CoV-2-M protein

A) Front and B) lateral view for the pharmacophore model for the Cov-2-M ${ }^{\text {Pro }}$ protein. Green spheres depict the hydrophobic segments $(\mathrm{Hy})$, blue spheres are the aromatic segments $(\mathrm{Ar})$, purple spheres represent the hydrophobic and aromatic segments (Hy-Ar), gray spheres depict the hydrogen donor segments (HD) and the orange sphere represents the hydrogen acceptor segments (HA).
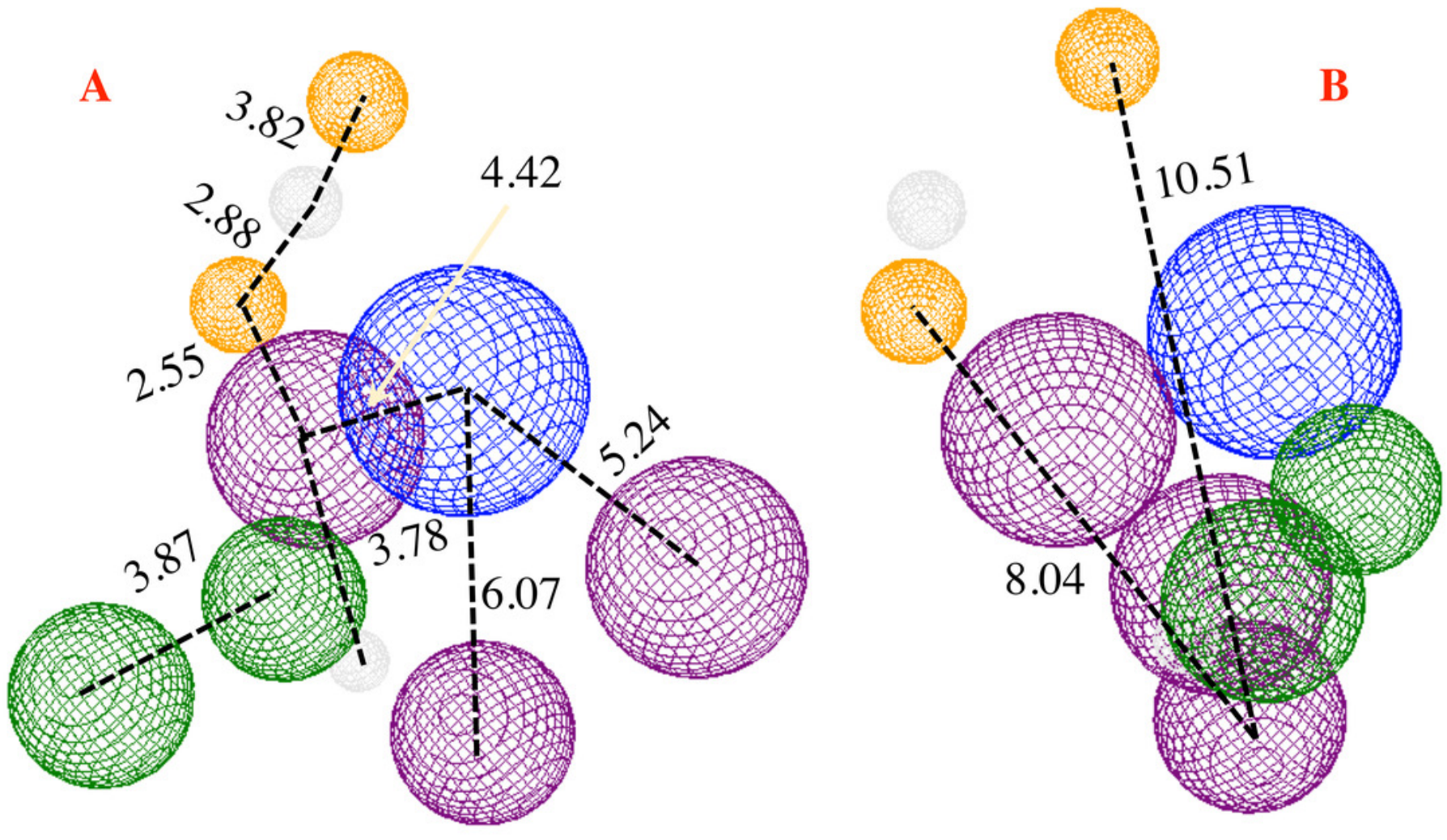


\section{Figure 7}

Designed compounds that present favorable interactions with the CoV-2-M $M^{\text {pro }}$ protein. 
A<smiles>N#Cc1ccc(-n2cc(CN(C(=O)O)C(c3ccc(Oc4ccccc4)cc3)c3nnnn3C3CCCCC3)nn2)cc1</smiles>

C<smiles>N#Cc1ccc(-n2cc(CN(C(=O)O)C(c3ccc(-c4ccncc4)cc3)c3nnnn3C3CCCCC3)nn2)cc1</smiles><smiles>N#Cc1ccc(-n2cc(CN(C(=O)O)C(c3ccc(COc4ccccc4)cc3)c3nnnn3C3CCCCC3)nn2)cc1</smiles><smiles>N#Cc1ccc(-n2cc(CNC(c3ccc(-c4ccccn4)cc3)c3nnnn3C3CCCCC3)nn2)cc1</smiles><smiles>N#Cc1ccc(-n2cc(CNC(c3ccc(-c4ccncc4)cc3)c3nnnn3C3CCCCC3)nn2)cc1</smiles><smiles>N#Cc1ccc(-n2cc(CNC(c3ccc(COc4ccccc4)cc3)c3nnnn3C3CCCCC3)nn2)cc1</smiles><smiles>N#Cc1ccc(-n2cc(CNC(c3cc4cc(N=C5C(=O)Nc6ccccc65)ccc4o3)c3nnnn3C3CCCCC3)nn2)cc1</smiles><smiles>N#Cc1ccc(-n2cc(CNC(c3ccc(Oc4ccc(O)cc4)cc3O)c3nnnn3C3CCCCC3)nn2)cc1</smiles><smiles>N#Cc1ccc(-n2cc(CNC(c3ccc(Oc4ccccc4)cc3)c3nnnn3C3CCCCC3)nn2)cc1</smiles> 


\section{Figure 8}

Non-covalent interactions between $\mathrm{p} 8$ and the CoV-2-M $\mathrm{M}^{\mathrm{pro}}$ protein

A) Hydrophobic, B) Hydrogen bond and C) electrostatic interactions between p8 and the Cov-2-Mpro protein. Blue surfaces represent hydrophobic sites, red surfaces are hydrophilic zones, dotted blue lines represent the hydrogen bond interactions, as well as the dotted green and red lines are the attractive and repulsive interactions, respectively. 

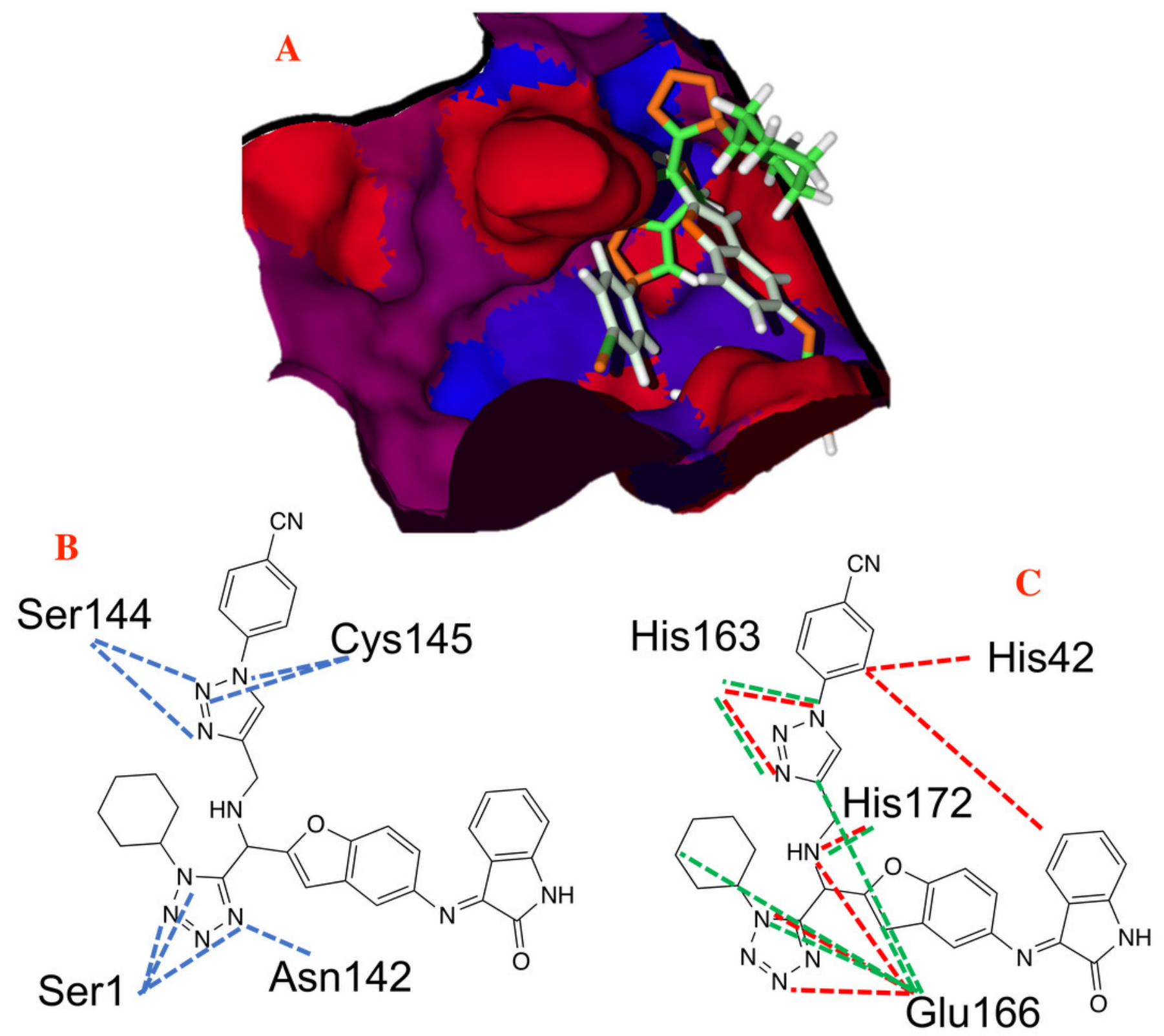


\section{Figure 9}

Main molecules overlap into the pharmacophore model for the CoV-2-M ${ }^{\text {pro }}$ protein

A) le and B) p8 molecules overlap into the pharmacophore model for the CoV-2-M protein.

Green spheres depict the hydrophobic segments (Hy), blue spheres are the aromatic segments (Ar), purple spheres represent the hydrophobic and aromatic segments (Hy-Ar), gray spheres depict the hydrogen donor segments (HD) and the orange sphere represents the hydrogen acceptor segments (HA).
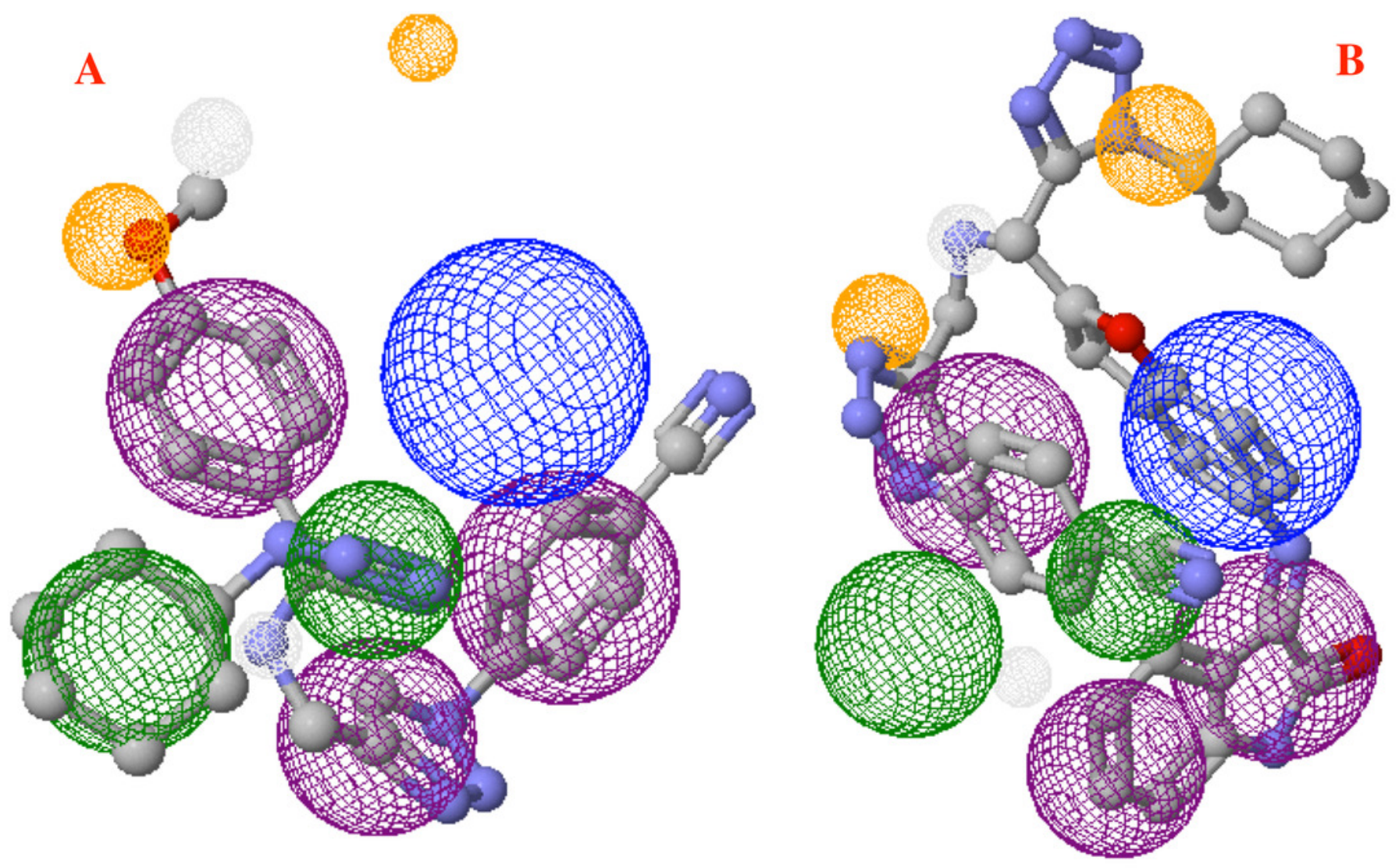